Penelitian

\title{
Morfometrik Pertumbuhan Rahang Bawah terkait Aktivitas Mandibula dan Umur pada Anakan Domba Merino Jantan Pascalahir
}

\author{
(Morfometry of Lower Jaw Growth Pattern \\ Related to Mandibule Functional and Ages of First Sixth Month of Life in Merino Lamb) \\ Benjamin C. Tehupuring*, Hana Eliyani, Soeharsono \\ Departemen Anatomi Veteriner, Fakultas Kedokteran Hewan, Universitas Airlangga \\ *Penulis untuk korespondensi: bencthp@yahoo.com \\ Diterima 5 Juni 2013, Disetujui 16 September 2013
}

\begin{abstract}
ABSTRAK
Penelitian ini bertujuan untuk membuktikan pola pertumbuhan rahang bawah (mandibula) domba merino jantan pada enam bulan pertama pascalahir tidak linier mengikuti pertambahan umur karena aktivitas feeding dipengaruhi olehnya. Model pendugaan MARS (Multivariate Adaptive Regression Splines) digunakan untuk pembuktian pola tersebut. Lima belas ekor anakan domba merino pascalahir diukur panjang dan lebar rahang bawah setiap selang satu bulan selama enam bulan. Data total panjang dan lebar mandibula $(\mathrm{cm})$ ditabulasi dan diolah dengan piranti MARS for Windows versi 2.0. Hasil analisis model MARS untuk hubungan umur terhadap panjang mandibula adalah $\mathrm{Y}=13,022+$ $0,933 * \mathrm{BF} 2\left\{\mathrm{BF} 2=\max (0\right.$, umur - 4,000) $\} ;\left\{\left(\mathrm{BF}=3, \mathrm{MI}=1, \mathrm{Mo}=0, \mathrm{GCV}=3,148, \mathrm{R}^{2}=0,984\right)\right\}$, sedangkan untuk lebarnya adalah $\mathrm{Y}=4,940+0,382 * B F 1+0,368 * B F 2\{B F 1=\max (0$, umur $-4,000)$ dan $B F 2=\max$ (0, 4,00-umur) $\} ;\left\{M I=1, M o=0, G C V=0,532\right.$ dan $\left.\left.R^{2}=0,984\right)\right\}$. Hasil ini menunjukkan pertambahan ukuran panjang ataupun lebar rahang bawah berjalan linier dengan umur setelah anak domba merino mencapai umur empat bulan, sedangkan ini masih di bawah umur empat bulan, hubungan tersebut tidak linier, bahkan pada rentang umur satu menuju empat bulan lebar mandibula justru menampakkan penyusutan. Pengamatan ini menyimpulkan bahwa, pola pertumbuhan bagian rahang bawah tidak berjalan linier dengan umur sebagai implikasi dari fungsi mandibula saat menyusu dan memamah-biak di awal pertumbuhan anakan domba merino.
\end{abstract}

Kata Kunci: rahang bawah, morfometrik mandibula, domba merino

\begin{abstract}
The study was carried out to investigate the pattern of lower jaw growth related to functional and ages in post-natal life of merino lamb. The MARS (Multivariate Adaptive Regression Splines) models was used to analyzed that assumed. A total of fifteen merino lambs were measured the length and width of the lower jaw that collected during one to six months of ages. Monthly measurements data were subjected to analysis by MARS for Windows version 2.0. The result of MARS model of the relationship between age and length lower jaw expressed in the equation $\mathrm{Y}=13.022+0.933$ * BF2; $\{(\mathrm{BF} 2=\max (0$, age - 4000) $\} ;\left\{\left(B F=3, M I=1, M o=0, G C V=3.148, R^{2}=0.984\right)\right\}$ and model of width lower jaw was $\{Y=$ $\left.4940+0382 * B F_{1}+0368 * B F 2\right\} ;\left\{B F 1=\max (0\right.$, age -4.000$)$ and $B F_{2}=\max (0,4.00-$ age $\left.)\right\} ;\{\mathrm{MI}=1, \mathrm{Mo}$ $=0, G C V=0.532$ and $\left.\left.R^{2}=0.984\right)\right\}$. It means as the lamb reaches up four months of age, the size both of length or width lower jaw increase linearly with age, meanwhile both measurement of the mandible growth were non-linearity as the young lambs below four month of age, especially the widht measure of mandible showed declined markedly with incresing of date. The result showing that the lower jaw growth pattern increased non linearity with age, because mandible have important function implication for feeding i.e. suckling and foraging during in the early stage of merino lamb life.
\end{abstract}

Key words: lower jaw, mandible morfometric, merino lamb 


\section{PENDAHULUAN}

Domba merino masuk ke Indonesia pada awal abad ke 19. Perkembangan domba jenis ini kurang pesat untuk wilayah tropis seperti di Indonesia, namun mengingat potensinya sebagai produsen bulu, maka budidaya domba merino memiliki peluang untuk dikembangkan. Penggalian pengetahuan dasar tetap diperlukan sebagai fundamen pengembangan ternak domba merino dikemudian hari. Upaya yang dilakukan adalah meneliti pola pertumbuhan rahang bawah sebagai bagian dari kepala hewan yang meregulasi aktivitas menyusu dan ruminasi pascalahir (Tiesnamurti \& Subandriyo, 2005).

Pertumbuhan ternak di awal kehidupan merupakan langkah penting untuk menghasilkan kinerja optimal di kemudian hari. Pertumbuhan dimanifestasikan oleh perubahan anatomi tubuh, menyangkut morfometri berupa ukuran panjang, lebar, volume maupun massa tubuh. Pertumbuhan bagian tubuh ditentukan oleh faktor genetik, disamping juga faktor lingkungan (Priyanto \& Subandriyo, 2011).

Salah satu pemeran proses kelangsungan hidup adalah sistem pencernaan yang dimulai dari rongga mulut sebagai penerima makanan. Secara anatomi tampak luar rongga mulut diwakili oleh dagu dan rahang bawah, dengan struktur pendukung berupa tulang rahang bawah (os mandibula), otot pemamah biak (musculus mastikasi) dan gigi geraham (Goldfinger, 2002).

Seekor anak domba merino mulai lahir hingga hari ke empat akan menyusui kolostrum induknya. Mulai awal minggu pertama hingga umur empat bulan, domba muda diprogram untuk menghisap susu/susu tambahan. Seusai lepas sapih anakan domba diberi pakan hijauan dengan tambahan konsentrat sehingga bagian rahang mulai terlatih untuk memamah biak (Gunawan \& Noor, 2007).

Periode feeding sepanjang enam bulan awal kehidupan ini memberi implikasi pada morfometri mandibula anakan domba merino sehingga pertumbuhan rahang bawah tidak berjalan linier bersama dengan bertambahnya umur. Analisis statistik yang digunakan untuk pendekatan pembuktian implikasi tersebut adalah dengan model pendugaan MARS yang memiliki tingkat akurasi tinggi (Yensy, 2007).

\section{BAHAN DAN METODE}

\section{Hewan Coba}

Hewan model berupa lima belas ekor anakan domba Merino jantan, dipilih sejak berumur satu bulan dengan bobot antara 11,0 hingga 12,0 kg. Domba dipelihara dan dikelola pakan maupun lingkungannya dengan kondisi yang sama pada peternakan di daerah Wonosalam, Kabupaten Jombang, Jawa Timur. Pasokan nutrisi, sejak umur seminggu hingga empat bulan, diberikan berupa susu induk dan air susu tambahan, lalu setelah umur empat bulan dilanjutkan dengan pakan hijauan dan tambahan konsentrat.

Teknik pengukuran morfometrik selama enam bulan tersebut dilakukan pengukuran terhadap panjang dan lebar rahang bawah setiap bulan terhadap setiap ekor domba. Pengukuran panjang mandibula dimulai dari titik terdepan dagu hingga ke titik sudut mandibula. Ukuran lebar mandibula diperoleh dengan mengukur jarak antara sudut mandibula kanan dan mandibula kiri (Gambar 1). Teknik ukur lebar mandibula ini mengikuti kaidah gonion yakni mengukur jarak dari titik paling bawah-posterior pada sudut yang terbentuk oleh ramus mandibulae (Glinka, 1990). Alat ukur yang digunakan berupa pita ukur dengan satuan centimeter $(\mathrm{cm})$.

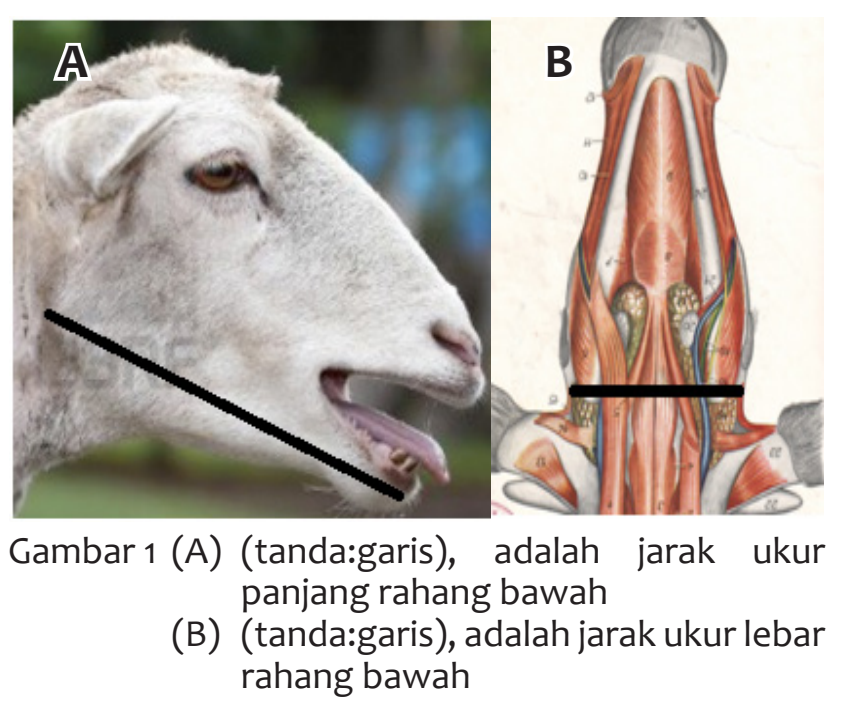

\section{Analisis Data}

Teknik analisis MARS (Multivariate Adaptive Regression Splines) merupakan metode estimasi alternatif yang dapat meningkatkan ketepatan pendugaan. Pada penelitian ini metode MARS diterapkan untuk menilai model hubungan, sehingga rumus permodelan yang dihasilkan dapat mengungkapkan pertambahan ukuran rahang bawah (panjang atau lebar) sebagai variabel yang diprediksi berjalan linier ataukah tidak terhadap peubah deret umur (sepanjang umur satu hingga enam bulan). 
Data pengukuran panjang dan lebar rahang bawah anak domba Merino setiap bulan selama enam bulan dianalisis dengan metode MARS dengan menampilkan gambar projeksi dan model hubungan antara ukuran mandibula dengan deret umur. Hasil model estimasi MARS berupa rumus: $\mathrm{Y}=\mathrm{B} 0+\mathrm{B} 1 * \mathrm{BF} 1+\mathrm{B} 2 * \mathrm{BF} 2+\ldots \mathrm{Bk} * \mathrm{BFk}$ dimana $\mathrm{Y}=$ ukuran mandibula; $\mathrm{BO}=$ konstanta; $\mathrm{B} 1, . ., . ., \mathrm{Bk}=$ koefisien basis fungsi spline; $\mathrm{BF} 1, . ., \ldots \mathrm{BFk}=$ basis fungsi ke $1,2, . . . . .$, ke-k. Kriteria model pendugaan ditetapkan berdasarkan besaran basis fungsi (BF) maximum; maksimal interaksi (MI); minimal pengamatan (Mo); nilai GVC (generalized cross validation; dipilih yang terkecil sedangkan angka R2 terkoreksi dipilih yang terbesar). Penghitungan dikerjakan dengan piranti MARS for Windows versi 2.0 (Yensy, 2007). Hasil model Mars diuji validitasnya dengan uji $t$ berpasangan dengan tingkat kepercayaan 95\% $(p<0,05)$.

\section{HASIL}

\section{Panjang Mandibula Estimasi MARS}

Model estimasi MARS dengan kriteria yang memenuhi untuk hubungan umur terhadap panjang mandibula adalah $\mathrm{Y}=13,022+0,933 * \mathrm{BF} 2(\mathrm{BF} 2=$ $\operatorname{Max}\left(0\right.$, umur - 4,00); $\mathrm{MI}=1 ; \mathrm{Mo}=0 ; \mathrm{GVC}=3,148 ; \mathrm{R}^{2}$ $=0,984)$, dimana $Y=$ panjang mandibula yang diduga, $\mathrm{BF}_{2}=\max (0$, umur $-4,00)$. Rumus ini berlaku untuk domba merino setelah umur di atas 4 bulan, yang ditunjukkan dengan nilai tidak berbeda nyata dengan ukuran sesungguhnya $\left(\mathrm{t}_{0,05,44}=0,647 ; \mathrm{p}=\right.$ $0,521)$. Ukuran estimasi madibula dapat dilihat pada Tabel 1 dan hasil model hubungan umur terhadap panjang mandibula disajikan melalui Gambar 2.

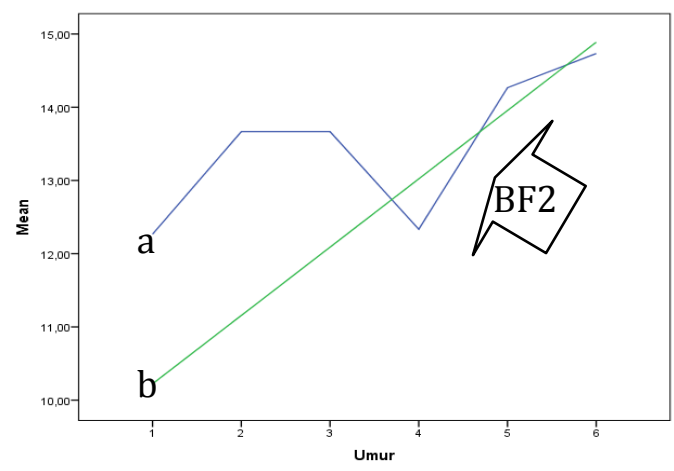

Gambar 2 Model hubungan antara umur (bulan) terhadap rataan panjang mandibula (cm) domba merino jantan pada awal pertumbuhan, (projeksi garis a) berdasarkan ukuran mandibula sebenarnya, (projeksi garis b) berdasarkan ukuran permodelan MARS; Tanda panah dan $\mathrm{BF}_{2}$ menandai garis a dan $\mathrm{b}$ yang tidak berbeda nyata $(p>0,05)$.

\section{Lebar Mandibula}

Model estimasi MARS dengan kriteria yang memenuhi untuk hubungan umur terhadap lebar mandibula adalah $\mathrm{Y}=4,940+0,382$ * $\mathrm{BF} 1+0,368$ * BF2. $(B F 1=\max (0$, umur $-4,000)$ dan $B F 2=\max (0$, 4.00 - umur); $M I=1, M o=0, G C V=0,532$ dan $R^{2}$ $=0,984)$. Fungsi yang pertama (BF1) menunjukkan model berlaku untuk peningkatan lebar mandibula anak domba setelah berumur empat bulan $\left(t_{0,05,59}\right.$ $=-0,110, p=0,913)$, sedangkan fungsi kedua $(B F 2) ;$ model berlaku untuk penurunan lebar mandibula ketika umur anak domba di bawah empat bulan $\left(t_{0,05,59}=0,088, p=0,930\right)$. Ukuran estimasi MARS untuk lebar mandibula dapat dilihat pada Tabel 2, sedangkan hasil model hubungan umur terhadap lebar mandibula disajikan melalui Gambar 3.

Tabel 1 Panjang mandibula anakan domba merino jantan (rataan \pm SD) hasil ukuran riil dan hasil ukuran estimasi MARS.

\begin{tabular}{|c|c|c|c|}
\hline \multirow{2}{*}{ Umur (bulan) } & \multicolumn{2}{|c|}{ Panjang Mandibula (cm) } & \multirow{2}{*}{ Hasil validasi } \\
\hline & Ukuran riil & Ukuran estimasi MARS & \\
\hline 1 & $12,27 \pm 1,75$ & 10,22 & Berbeda nyata \\
\hline 2 & $13,67 \pm 1,34$ & 11,16 & Berbeda nyata \\
\hline 3 & $13,67 \pm 1,34$ & 12,09 & Berbeda nyata \\
\hline 4 & $12,33 \pm 1,45$ & 13,02 & Tidak berbeda nyata \\
\hline 5 & $14,27 \pm 1,87$ & 13,95 & Tidak berbeda nyata \\
\hline 6 & $14,73 \pm 2,12$ & 14,89 & Tidak berbeda nyata \\
\hline
\end{tabular}

\footnotetext{
*) hitungan hasil program MARS for Windows versi 2.0
} 
4 | Tehupuring et al.

Tabel 2 Lebar mandibula anakan domba merino jantan (rataan \pm SD) hasil ukuran riil dan hasil ukuran estimasi MARS.

\begin{tabular}{cccc}
\hline \multirow{2}{*}{ Umur (bulan) } & \multicolumn{2}{c}{ Lebar Mandibula $(\mathrm{cm})$} & Hasil validasi \\
\cline { 2 - 3 } & Ukuran riil & Ukuran estimasi MARS ${ }^{*}$ & \\
\hline 1 & $6,13 \pm 1,06$ & 6,04 & Tidak berbeda nyata \\
2 & $5,47 \pm 0,52$ & 5,68 & Tidak berbeda nyata \\
3 & $5,47 \pm 0,52$ & 5,31 & Tidak berbeda nyata \\
4 & $4,93 \pm 0,59$ & 4,94 & Tidak berbeda nyata \\
5 & $5,27 \pm 0,73$ & 5,32 & Tidak berbeda nyata \\
6 & $5,73 \pm 0,70$ & 5,70 & Tidak berbeda nyata \\
\hline
\end{tabular}

*) ukuran ini dihasilkan melalui program MARS for Windows versi 2.0;

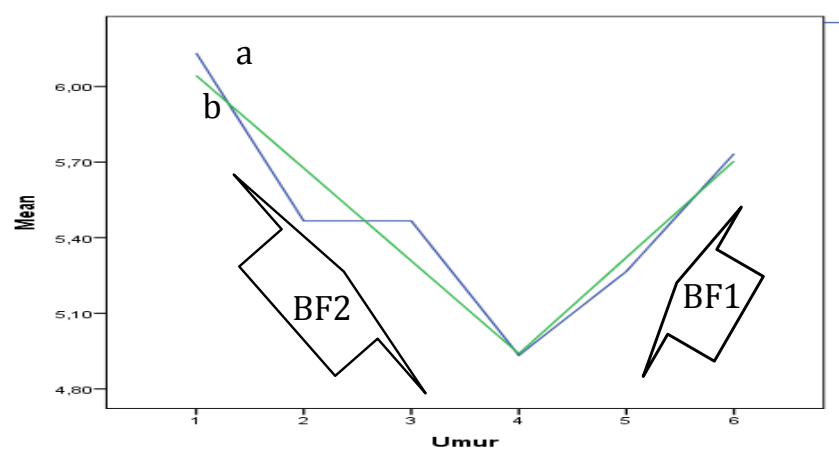

Gambar 3 Model hubungan antara umur (bulan) terhadap rataan lebar mandibula $(\mathrm{cm})$ domba merino jantan pada awal pertumbuhan. (Projeksi garis a) berdasarkan ukuran mandibula sebenarnya; (Projeksi garis b) berdasarkan ukuran permodelan MARS. Tanda panah dan $\mathrm{BF} 1 / \mathrm{BF} 2$ menandai garis a \& garis b yang tidak berbeda nyata $(p>0,05)$.

\section{PEMBAHASAN}

Pemodelan MARS pada prinsipnya memiliki derajat ketepatan yang tinggi untuk melakukan estimasi. Hasil telaah pemodelan peramalan panjang dan lebar rahang bawah berdasarkan pertambahan umur anakan domba merino umur satu hingga enam bulan menunjukkan pertambahan ukuran panjang ataupun lebar rahang bawah akan berjalan linier dengan pertambahan umur setelah domba merino mencapai umur empat bulan dan berlangsung terus hingga domba berumur enam bulan pada penelitian ini. Sementara itu, saat umur anak domba masih di bawah empat bulan, pertambahan panjang rahang bawah ini tidak berlangsung linier, bahkan terungkap ukuran lebar mandibula menampakkan kecenderungan menyusut saat umur domba antara satu sampai empat bulan.
Pola ini memperkuat dugaan bahwa sejumlah faktor ikut berperan membentuk perubahan anatomis bagian rahang bawah. Faktor tersebut diantaranya nutrisi, sinar matahari, sekresi hormonal dan olah fisik. Olah fisik bagian rahang bawah akan melibatkan os mandibulae sebagai tulang pendukungnya. Peregangan terhadap tulang akan menstimulasi proses kalsifikasi dan deposisi osteoblastik pada tulang, termasuk daya kontraksi otot yang bertaut padanya. Tulang mandibula berkembang alamiah bersamaan dengan aktivitas hewan saat memenuhi tuntutan kehidupan, seperti menyusu pada anak domba pascalahir dan mulai berlatih memamah biak setelah disapih (Langvatn et al., 2004).

Pola pemberian pakan pada anakan domba merino mengikuti urutan standar yakni pada umur satu hingga empat hari diberi susu kolostrum induknya. Selanjutnya mulai umur seminggu anak domba diberi susu pengganti hingga usia empat bulan. Setelah empat bulan anak domba disapih dan sepenuhnya diberi pakan hijauan dan konsentrat (Gunawan \& Noor, 2007).

Tulang pipih diantaranya cranium dan mandibula, berkembang melalui proses ossifikasi intramembraneous. Materi dasarnya adalah fibril kolagen dan jaringan ikat mesenkim yang relatif lunak. Mesenkim berproliferasi menjadi osteoblas membangun area pusat penulangan. Osteoblas akan memproduksi matriks tulang (osteoid). Matrik tulang yang disekresi akan mengurung osteoblas untuk membentuk osteosit sementara matrik tulang yang lebih tua akan mengalami kalsifikasi. Pada bulan pertama pasca lahir, matrik tulang dan fibril kolagen yang lunak masih mendominasi tenunan tulang. Sejalan dengan waktu anak domba mendapat air susu yang kaya mineral kalsium, maka matriks yang diproduksi tenunan tulang akan mengalami 
kalsifikasi. Osteoblas makin bertambah jumlahnya dan makin meluas, walaupun tetap terkonsentrasi di periosteum, sementara tenunan tulang yang paling dalam dibiarkan berongga (trabekula). Matriks tulang yang terakumulasi di periosteum bersama barisan osteoblas adalah lapisan yang membangun kekerasan dan kekompakan tulang pipih mandibula ini (Gilbert, 2000).

Teori dasar di atas menjelaskan bahwa massa tulang pascalahir belum mengalami kalisifikasi sempurna, karena didominasi oleh fibril kolagen dan matrik tulang yang relatif cair dan lunak. Struktur massa tulang os mandibula yang lunak ini mempengaruhi ukuran lebar rahang bawah domba pada bulan pertama pasca lahir, sekalipun melebar namun masih lunak.

Sejalan dengan waktu antara umur satu sampai empat bulan, ukuran rahang terlihat menyusut. Diduga kuat, hal ini merupakan implikasi dari pertumbuhan tenunan tulang os mandibula, walaupun osteoblas banyak terbentuk namun susunannya terbatas di periosteum, sedangkan matriks dan fibril kolagen di sekitarnya yang semula lunak, kini membangun struktur tulang makin keras dan kompak oleh asupan kalsium dari air susu. Aktivitas menyusu induk atau menghisap botol susu semasa tersebut melibatkan kontraksi otot dinding pipi ( $m$. buccinator) dan otot lidah (m. stylohyoideus, geniohyoideus, mylohyoideus dan thyrohyoid). Pada periode ini belum terjadi peregangan otot di posisi rahang, sehingga os mandibula dan sendi rahang hanya bekerja pasif (Thexton, 2012).

Selepas sapih domba merino memasuki umur empat bulan. Ternak ini diberi pakan berupa hijauan dan konsentrat. Kegiatan ruminasi oleh rahang bawah mulai diaktifkan. Os mandibula sebagai tautan tendo otot mastikasi (m. pterygoideus dan m. masseter) mulai berkontraksi. Demikian pula articulatio temporamandibulare serta gigi geraham yang tumbuh di tulang rahang bergerak aktif menggiling hijauan (Langvatn et al., 2004; Priyanto \& Subandriyo, 2011).

Langvatn et al. (2004) mengamati morfometrik proporsi relatif panjang mandibula yang diukur pada periode fetus hingga rusa merah mencapai umur 5 tahun menunjukkan kecenderungan adanya penurunan dan ini sangat ditentukan oleh faktor asupan nutrisi dan aktivitas merumput.

Daniel et al. (2003) membuktikan bahwa struktur tulang memiliki kemampuan adaptasi yang cukup besar terhadap tekanan mekanis yang kontinyu. Adaptasi ini secara histomorfometrik ditunjukkan oleh domba umur 3 bulan yang dipacu jalan di tempat selama 60 menit per hari, selama 90 hari.
Akibatnya terjadi penambahan massa tulang pada sisi permukaan tulang yang dibebani aktivitas fisik. Secara histologik, terlihat pertambahan luas permukaan distal dan jumlah sistem haversi pada os metacarpal. Jika dibandingkan dengan domba kontrol penambahannya mencapai $21,3 \%$ dan $107 \%$.

Analisis hasil pengamatan pada domba merino ini memperlihatkan bahwa morfometri bagian rahang bawah mempunyai pola pertumbuhan beradaptasi terhadap pola pemberian pakan. Kecenderungan penyusutan ukuran lebar berlangsung saat hewan masih menyusu dan minum susu, kemudian pertambahan panjang dan lebar rahang bawah meningkat perlahan setelah periode ruminasi yang dimulai umur 4 bulan.

Berdasarkan telaah peneliti lain, dilaporkan bahwa kecepatan pertambahan panjang mandibula yang tidak linier dengan umurjuga diperlihatkan oleh kelinci, tikus dan mencit (Zoetis et al., 2003). Pada babi, perbedaan ukuran mandibula terkait dengan umur lebih disebabkan oleh pertumbuhan gigi. Tetapi ukuran mandibula dapat juga dipengaruhi faktor lokasi pemeliharaan dengan kata lain faktor ekologi dan perilaku dapat mempengaruhi ukuran panjang mandibula (Olopade \& Okandeji, 2010).

Kesimpulan dari hasil penelitian yang dilakukan terhadap anak domba merino ini menunjukkan bahwa aktivitas menyusui sebelum usia empat bulan dan memamah biak hijauan pascasapih merupakan salah satu faktor berpengaruh selain umur terhadap pola pertumbuhan rahang bawah (mandibula).

"Penulis menyatakan tidak ada konflik kepentingan dengan pihak-pihak terkait dalam penelitian ini"

\section{DAFTAR PUSTAKA}

Daniel EL, Pearson OM, Polk JD, Demes B, Crompton AW. 2003. Optimization of bone growth and remodelling in respon to loading in tapered mammalian limbs. The Journal of Experimental Biology 206: 3125-3138.

Glinka J. 1990. Antropometri dan antroposkopi. Ed. 3. Fakultas Imu Sosial dan Politik Universitas Airlangga. Surabaya.

Goldfinger E. 2002. Animal Anatomy for Artists: The Elements of Form Eliot Goldfinger. Oxford University Press. New York.

Gunawan A, Noor RR. 2006. Pendugaan nilai heritabilitas bobot lahir dan bobot sapih domba garut. Media Peternakan 29(1): 7-15. 
6 | Tehupuring et al.

Langvatn R, Mysterud A, Stenseth NC. 2004. Relationships in red deer Cervus elaphus mandible. Acta Theriologica 49(4): 527-542.

Olopade JO, Okandeji ME. 2010. A study of some rostrofacial indices related to regional anaesthesia of the porcine: implications as an animal model for dental research. Niger Journal of Physiologic Science 25: 159-164.

Priyanto D, Subandriyo. 2011. Uji adaptasi domba komposit pada kondisi usaha peternakan rakyat di pedesaan. Seminar Nasional Teknologi Peternakan dan Veteriner. 577-585.

Thexton AJ, Crompton AW, German RZ. 2012. EMG activity in hyoid muscles during pig suckling. Journal of Applied Physiology 12(9): 1512-1519.
Tiesnamurti B, Subandriyo. 2005. Tingkah laku beranak domba merino dan sumatera yang dikandangkan. Seminar Nasional Teknologi Peternakan dan Veteriner,505-511.

Yensy NA. 2007. Pengunaan regresi spline adaptif berganda untuk peramalan indeks enso dan hujan bulanan. Exacta FKIP Bengkulu 2: 105-113.

Zoetis T, Tassinari MS, Bagi C, Walthall K, Hurtt ME. 2003. Species comparison of postnatal bone growth and development. Birth Defects Research (Part B) 68: 86-110. 